\title{
Up Close: The Advanced Materials Institute
}

\author{
Jerome G. Morse \\ Editor's Note: This is the ninth article in a series focusing on the research capabilities and goals of interdisciplinary laboratories \\ pursuing materials research in universities, industry, and government.
}

\section{A Colorado Consortium}

The Advanced Materials Institute (AMI) is the materials research arm of the Colorado Advanced Technology Institute (CATI), a state agency created in 1983 by the state General Assembly as an economic development initiative involving academic, industry, and government sectors. AMI represents a unique process in academic research: long-term materials needs of industry members are addressed by university investigators, with federal agencies providing the major source of funding.

AMI is a consortium of four research universities (Colorado School of Mines as the lead institution, Colorado State University, and the Universities of Colorado and Denver) and a present industrial membership of nine corporations (AMAX Inc., Adolph Coors Company, Digital Equipment Corporation, Gates Company, Hewlett Packard, IBM, Manville, Martin Marietta, and Telectronics). The Institute is governed by a Board of Directors with representatives from each participating organization. Sustaining memberships, which do not include representation on the Board, are available; memberships of both kinds are open to non-Colorado-based companies.

\section{How the AMI Concept Works}

The long-term materials needs of industry members provide AMI's research agenda; many items, once identified, become company-shared interests. Requests for proposals, based on the agenda, are distributed to the affiliated universities for competitive awarding of seed funds. Proposals receive peer review and the Board selects those to be funded. Projects arising from the winning proposals then seek full funding through conventional proposal routes from federal and other agencies.

Seed grants have been limited so far to $\$ 5,000$, enabling only minimal support of a graduate student, purchase of supplies, etc., but enough to give the proposer a competitive edge in marketing the proposal. Although too small to support research, this amount does establish a tangible basis for interaction between the participating schools and the companies.

Seed proposals received by AMI often constitute innovative approaches not previously considered by a company in defining its needs. Companies have teamed with participating universities to open new lines of research independent of federal funding.

A consortium such as this enables combining the specialized capabilities of

two universities to focus on a single problem, reducing research and equipment duplication.

\section{Overview of Results}

As AMI begins its third year, the 25 awards authorized to date have resulted in seven major grants which now exceed $\$ 2.3$ million; 15 more proposals are either under review or being written. Each grant obtained in this manner represents a project, initially defined by company members, which also reflects the mutual interests of

\section{AMI PROCESS FLOW}
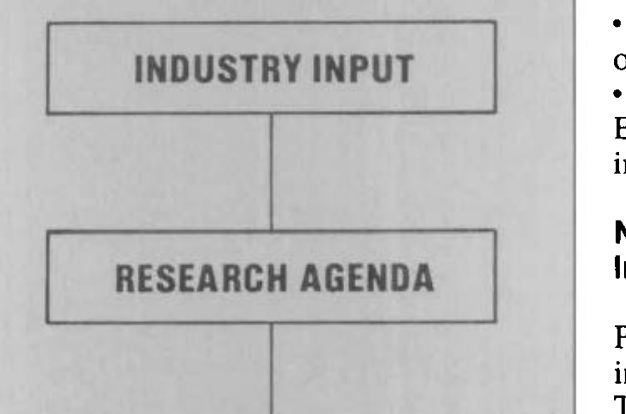

AMI hosted its first national conference AMI hosted its first national conference 